\title{
A preliminary study for evaluating immediate post- vibration effects of whole body vibration on postural control
}

\author{
Izzet KIRKAYA ${ }^{1}$, Deniz SIMSEK ${ }^{2}$, Abdullah Ruhi SOYLU ${ }^{3}$ \\ ${ }^{1}$ Department of Physical Education and Sports, Bursa Technical University, Bursa, Turkey. \\ ${ }^{2}$ Faculty of Sports Science, Anadolu University, Eskisehir, Turkey. \\ ${ }^{3}$ Biophysics Department, Faculty of Medicine, Hacettepe University, Ankara, Turkey.
}

\begin{abstract}
The aim of the preliminary study was to evaluate body sways simultaneously in mediolateral (ML) and anteroposterior (AP) directions of postural control measurements immediately after vibration stimulus. The participants were exposed to vibration stimulus for $60 \mathrm{~s}$ time period in static squat position with $150^{\circ}$ knee flexion on force platform that is placed on vibration platform. The vibration stimulus was given by a Compex WINPLATE Galileo 2000 device in up-down direction. Vibration amplitude and frequency were $2 \mathrm{~mm}$ and $40 \mathrm{~Hz}$ respectively. Each subject's recording time was $70 \mathrm{~s}(5 \mathrm{~s}$ rest, $60 \mathrm{~s}$ vibration and $5 \mathrm{~s}$ rest) for all sessions. The subjects stayed on the force measuring platform during each $70 \mathrm{~s}$ recording session. Soft mat of the vibration platform was placed between the vibration and force measuring platforms for reliable data and to prevent any damage on the force device. ML and AP force values normalized with respect to body weights for each subject. There were no statistically significant differences between the pre-vibration and post-vibration normalized force values. So, we claim that post-vibration effects are not statistically detectable unless a posture disturbance factor (for example moving from vibration device to force measurement device) occurs. The present study can be used as a reference to pave the way for the development an effective and sensitive measurement protocol of postural control.
\end{abstract}

Keywords: Force platform, postural sway, whole body vibration.

\section{INTRODUCTION}

Whole Body Vibration exercise has become increasingly popular and has sparked considerable interest, particularly among elite athletes and researches $(2,5,6,8)$. Although researchers have been interested in the effects of mechanical vibration on different human systems and tissues, the knowledge about vibration effects on postural stability is still unsatisfactory and the available studies present conflicting results (7). Researchers apply different vibration parameters (frequency and amplitude), vibration training procedures and measurement protocols. Therefore, Whole Body Vibration (WBV) on balance have provided controversial results with the use of different platform settings. In vibration literature, first subjects are exposed to vibration stimulus and then they move from the vibration device to the force measuring platform to measure postural sway $(7,11)$. The effect of vibration on balance studies have shown different results like balance enhancement $(4,9,10)$, no significant results $(8,12)$, and a reduction in overall postural stability (3).

There were no studies that investigate the effect of vibration immediately after ceasing of the vibration (i.e. subject stays on vibration device without moving from the vibration platform to the force platform). For the first time we measured real and immediate post vibration effect that does not include subject's movement (from vibration device to measuring device). The experiment presented in this article aimed to assess the real and immediate post vibration effect on the AP and ML postural stability in healthy subjects. Our specific hypothesis was that the post-vibration effects are not statistically detectable without a posture disturbance factor (for example, moving of subjects from the vibration 
device to the force measurement device) after the cessation of the vibration.

\section{MATERIALS \& METHODS}

\section{Subjects}

Twenty-four healthy subjects (Age: $23.9 \pm 3.17$ yrs, Weight: $74.3 \pm 9.4 \mathrm{~kg}$, Height: $176.3 \pm 8.1 \mathrm{~cm}$ ) who had no contraindications associated with WBV (epilepsy, diabetes, gallstones, kidney stones, acute inflammations, joint problems, cardiovascular diseases, joint inflammation, thrombosis, and back problems such as hernias or tumors) were included in the study. The University of Osmangazi Human Research Ethics Board approved this study, and subjects provided their informed written consent prior to participation.

This investigation used a repeated measures design to determine the effects of static WBV on the postural control responses. Before the experimental protocol, a WBV adaptation session was performed for all the subjects. Standing on vibration platform range to $110^{\circ}-150^{\circ}$ knee flexion shows higher muscle activity (1). Thus we asked to perform unloaded static squats with a knee flexion angle of $150^{\circ}$ from subjects. Knee joint angle changes were monitored by an electronic goniometer and the subjects received instantaneous feedback via a computer screen. Duration of each recording session was $70 \mathrm{~s}$ (5s rest, $60 \mathrm{~s}$ vibration and $5 \mathrm{~s}$ rest without any interruptions). During each $70 \mathrm{~s}$ recording session the subjects stayed on the force measuring platform.

\section{Data Collection Instruments}

The vibration platform was placed under the force measuring platform (See Figure 1). A soft mat (Compex Winplate Soft Mat 6522002) was placed between the platforms. The measurements were initiated when the subjects were comfortable at the squat position on the force platform.

\section{Data Collection}

For force measurement, a 600×400x100 mm "Kistler (Germany) 9281EA" force platform was used. The vibration measurements were produced using a Compex WINPLATE Galileo 2000 (Novotec Medical $\mathrm{GmBH}$, Germany) in up-down direction. Sampling rate for force data was $2000 \mathrm{~Hz}$ and force signals were normalized with respect to body weight.

\section{Data Analysis}

Normalized AP and ML force values were recorded and analyzed. After filtering ( $8^{\text {th }}$ degree Butterworth low pass filter with $10 \mathrm{~Hz}$ cut-off frequency) the rms (root-mean-square) values of every consecutive $500 \mathrm{~ms}$ weight normalized force signals were calculated. For statistics, mean normalized force values of the first $5 \mathrm{~s}$ rest periods were compared with the last ten rms values of the post vibration rest period (i.e. 'mean of $0^{\text {th }}$ to $5^{\text {th }} s^{\prime}$ vs. 'rms of $60^{\text {th }}$ to $60.5^{\text {th }} \mathrm{s}^{\prime}, \ldots$, 'mean of $0^{\text {th }}$ to $5^{\text {th }} \mathrm{s}^{\prime} \mathrm{vs}$. ' $r m s$ of $64.5^{\text {th }}$ to $65^{\text {th }} \mathrm{s}^{\prime}$ ). Student-t test was used to compare for two variables such as before and after vibration sway datas and the level of significance was set at $\mathrm{p}<0.05$. As control of vibration records, $70 \mathrm{~s}$ static posture force signals was also recorded (i.e. the subjects were at the squat position without any vibration) before the vibration sessions. The only difference between the vibration and the control recordings was the lack of vibration.

\section{RESULTS}

Figure 2 and 3 shows the weight normalized force (AP and ML) graphs. There were no statistically significant differences between the pre-vibration and post-vibration normalized force values. The same results were found for the control recordings also.

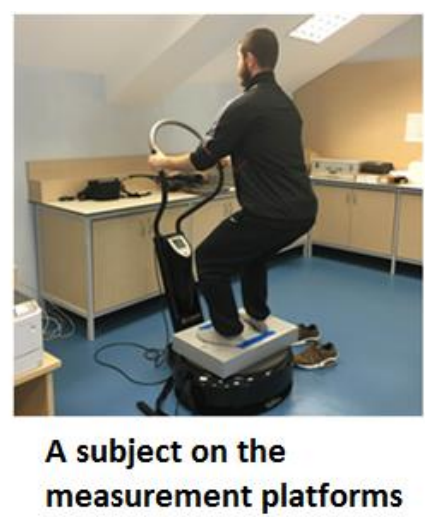

Figure 1. The force measuring platform was placed on the vibration device. There was a soft mat between the devices. 


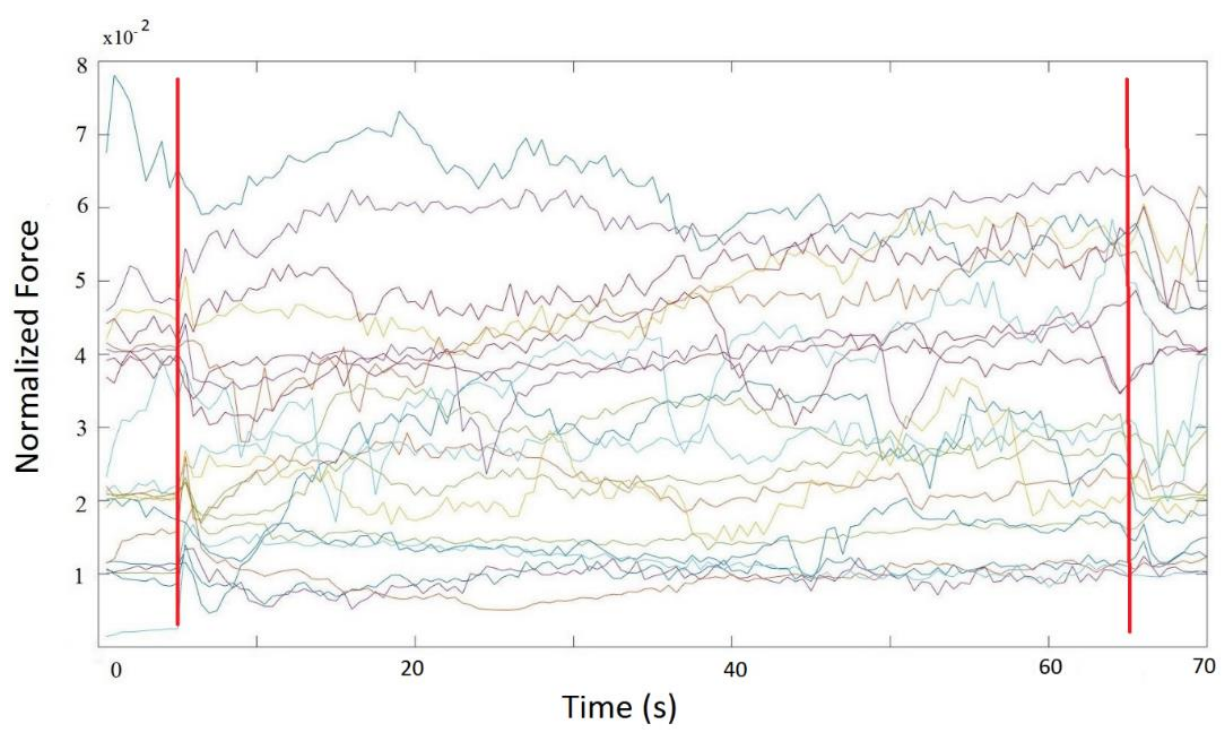

Figure 2. Weight normalized mediolateral reaction force graph of the subjects. Vertical lines show the beginning and the end of the vibration.

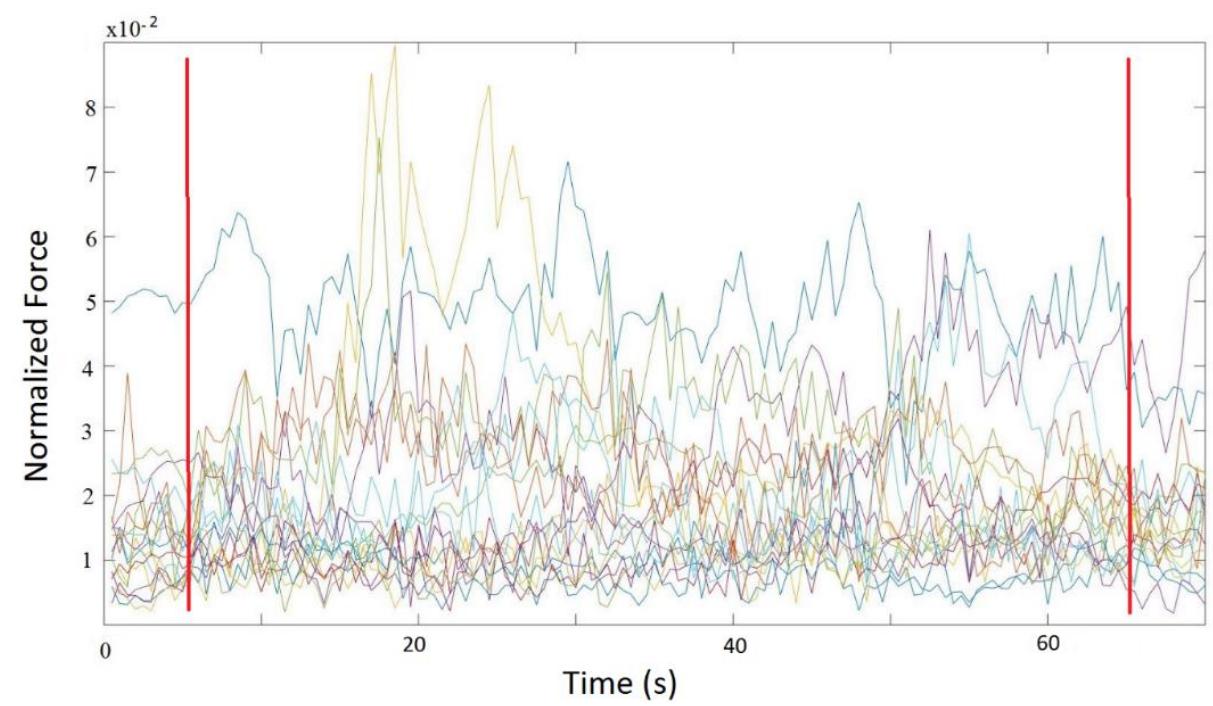

Figure 3. Weight normalized anteroposterior reaction force graph of the subjects. Vertical lines show the beginning and the end of the vibration.

\section{DISCUSSION}

In vibration literature, vibration exposed subjects move from vibration device to force measurement device to measure post-vibration sway. However, in these studies researchers do not measure pure post-vibration sway but also effect of the movement from the vibration device to the force measuring device. In other words, the sway recordings depend on movement from the vibration device to the force measuring device also. For the first time we measured real and immediate post vibration effect that does not include subject's movement (from vibration device to measuring device). Our statistical results showed that there were no statistical sway differences (before and after-vibration) due to the vibration (This conclusion doesn't mean that vibration has no effects on subjects).

We placed a soft mat that specifically produced for the vibration device between the platforms. Aims of inserting the mat between the devices were to prevent deterioration of the sensors of the force platform and to get reliable results. The statistical results showed that the rest values (pre vibration, post vibration and control rest values) did not show any statistical differences. It can be easily estimated that the measured force data are greatly affected by the setting condition (i.e. when a force plate is placed on a non-stiff base, the signal might become unreliable). Nevertheless, in our study we statistically compared the force data during rest, not 
during vibration (i.e. vibration device does not move during rest period so the results probably are not unreliable). Furthermore, we tested the force device after the study and couldn't find any problems (this does not mean that force sensors were not deteriorated in the mid and long terms). Lastly, there is a probability that after the vibration the force sensors might deteriorate temporarily. However, it should not be forgotten that, a) we compared all rest values (pre vibration, post vibration and control rest values) and couldn't find any statistical differences (the post vibration rest values are similar to the control values, so the results are probably reliable), b) this is a preliminary study and the future studies can disprove our method and results. If justified by further studies, the previous studies with different protocols/methods probably can be interpreted (or may be repeated) with the new approach to illuminate the post vibration effects. These method could be use easily with other combine trainings like electromyostimulation and even will be use with surface emg studies. Hence we can detect anteroposterior and mediolateral sway differences without disturb subject. Disturbance effect such as waiting after exercise bout, step down from platform etc. may lead post vibration sway results unclear.

The post-vibration effects are not statistically detectable without a posture disturbance factor (for example, moving of subjects from the vibration device to the force measurement device) after the cessation of the vibration.

\section{ACKNOWLEDGEMENT}

The current study was supported by Anadolu University (Project number: Anadolu Uni./ BAP 1207S116).

\section{REFERENCES}

1. Abercromby AFJ, Amonette WE, Layne CS, McFarlin BK, Hinman MR, Paloski WH. Variation in neuromuscular responses during acute whole-body vibration exercise. Medicine \& Science in Sport \& Exercise, 2007; 39(10):1794-800.
2. Bogaerts A, Verschueren S, Delecluse C, Claessens AL, Boonen S. Effects of whole body vibration training on postural control in older individuals: a 1 year randomized controlled trial. Gait \& Posture, 2007; 26(2): 309-316.

3. Dickin DC, McClai, MA, Hubble RP, Doan JB, Sessford D. Changes in postural sway frequency and complexity in altered sensory environments following whole body vibrations. Human Movement Science, 2012; 31(5): 1238-1246.

4. Lopez DG, Garatachea N, Marin PJ, Martin T, Herrero AJ. Acute effects of whole-body vibrations on balance maximal force and perceived exertion: Vertical platform versus oscillating platform. European Journal of Sport Science, 2011; 12(5): 425-430.

5. McGraw B, McClenaghan BA, Williams HG, Dickerson J, Ward, DS. Gait and postural stability in obese and nonobese prepubertal boys. Archives of Physical Medicine and Rehabilitation, 2000; 81(4): 484-489.

6. Palmieri R, Ingersol, C, Stone M, Krause A. Center-of-Pressure parameters used in the assessment of postural control. Journal of Sport Rehabilitation, 2002; 11(1): 51-66.

7. Piecha M, Krol P, Juras G, Sobota G, Polak A, Bacik B. The effect of short - and long - term vibration training on postural stability in men. Acta of Bioengineering and Biomechanics, 2013; 15(3): 29-35.

8. Pollock RD, Provan S, Martin FC, Newham DJ. The effects of whole body vibration on balance, joint position sense and cutaneous sensation. European Journal of Applied Physiology, 2011; 111(12): 3069-3077.

9. Ritzmann R, Kramer A, Bernhardt S, Gollhofer A. Whole body vibration training improving balance control and muscle endurance. Plos One, 2014; 9(2): 1-8.

10. Schlee G, Reckmann D, Milani TL. Whole body vibration training reduces plantar foot sensitivity but improves balance control of healthy subjects. Neuroscience Letters, 2012; 506(1): 70-73.

11. Sonza A, Robinson CC, Achaval M, Zaro MA. Whole body vibration at different exposure frequencies: infrared thermography and physiological effects. The Scientific World Journal, 2015; 2015:452657. doi: 10.1155/2015/452657.

12. Torvinen S, Kannus P, Sievanen H, Järvinen TA, Pasanen M, Kontulainen S, Nenonen A, Järvinen TL, Paakkala T, Järvinen $\mathrm{M}$, Vuori I. Effect of 8-month vertical whole body vibration on bone, muscle performance, and body balance: a randomized controlled study. Journal of Bone and Mineral Research, 2003; 18(5): 876-884. 